\title{
К ОПРЕДЕЛЕНИЮ КОЛИЧЕСТВА СОСЛАННЫХ В СИБИРЬ УЧАСТНИКОВ ЯНВАРСКОГО ВОССТАНИЯ 1863 ГОДА
}

\begin{abstract}
АНнОтАЦИЯ. Статья посвящена проблеме определения численности сибирских ссыльных - участников Январского восстания 1863 г. в отечественной и польской историографии. Установление подлинного количества ссыльных поляков в Сибири в 1863-1883 гг. - действительно, одна из ключевых задач сибирско-польской истории, научной и публицистической литературы. Ее неизменная излишняя политизация в 1920-1990-х гг. приводила исследователей к искаженным выводам, что, безусловно, негативно сказывалось на изучении сложной и порой противоречивой политической истории России и Польши XIX - начала $\mathrm{XX}$ в. Между тем решение проблемы - в преодолении учеными сложившихся стереотипов и идеологических штампов, в использовании новых групп ранее неопубликованных источников, в непредвзятом прочтении уже известного фактического материала, связанного с историей российской карательной и пенитенциарной политики, а также в координации исследований современных российских и польских специалистов.
\end{abstract}

кЛЮчЕВЫЕ СЛОВА. Политическая ссылка, поляки; Январское восстание 1863 года; Сибирь; Иркутская губерния.

ИНФОРМАЦИЯ О СТАТЬЕ. Дата поступления 10 октября 2016 г.; дата принятия к печати 2 ноября 2016 г.; дата онлайн-размещения 30 ноября 2016 г.

A. A. Ivanov Irkutsk State University, Irkutsk, Russian Federation

S. I. Kuznetsov

Irkutsk State University, Irkutsk, Russian Federation

\section{ON DETERMINING THE NUMBER OF THE JANUARY 1863 REVOLT PARTICIPANTS EXILED TO SIBERIA}

ABSTRACT. The Article is devoted to the problem of determining the number of the Siberian exiled - the participants of the January 1863 revolt in domestic and Polish historiography. Specifying the true number of exiled Poles in Siberia in 1863-1883 is indeed one of key problems of the Siberian-Polish history, scientific and publicistic literature. Her invariable excessive politicization in the 1920-1990th years led researchers to the distorted conclusions that, certainly, negatively affected studying of difficult and sometimes contradictory political history of Russia and Poland XIX - the beginnings of the 20th century. Meanwhile a solution - in overcoming by scientists the developed stereotypes and ideological stamps, in use of new groups of earlier unpublished sources, in impartial reading of already known actual material connected with history of the Russian retaliatory and penitentiary policy and also in coordination of researches of modern Russian and Polish experts.

KEYWORDS. Political exile; Poles, January revolt of 1863; Siberia; Irkutsk province. ARTICLE INFO. Received October 10, 2016; accepted November 2, 2016; available online November 30, 2016.

(C) А. А. Иванов, С. И. Кузнецов, 2016

\section{Baikal Research Journal}


Определение численности поляков участников Январского восстания, высланных в 1863-1870-х гг. в Сибирь - научная проблема, имеющая свою многолетнюю, а точнее, более чем полуторавековую историю. Первым ее исследователем «с российской стороны» по праву считается С. В. Максимов [1, с. 451]. В 18601861 гг. этот известный этнограф побывал на Дальнем Востоке России для исследования только что приобретенной Амурской области. На обратном пути ему было поручено составить обозрение сибирских тюрем и быта ссыльных, в результате чего появилась книга под названием «Тюрьма и ссыльные». Сначала она была издана в качестве служебной записки тиражом всего в 500 экземпляров, а затем в дополненном виде - уже как «Сибирь и каторга» (1871 г.) [2, ст. 444-445].

Труд С. В. Максимова действительно представляет значительный интерес в качестве ценного и разнопланового источника по истории сибирской ссылки XVII-XIX вв. Книга содержит многочисленные фактические сведения, рассказы и свидетельства современников. Исторические анекдоты соседствуют здесь с официальной статистикой, анкетные данные - с отрывками из работ Е. Н. Анучина, неопубликованные архивные материалы - с личными впечатлениями автора все, без чего не обойтись ни одному исследователю этой темы. Наконец, живой и увлекательный язык книги делает ее понятной, интересной и доступной любому современному читателю.

Легкость изложения не помешала С. В. Максимову поставить и по-своему решить несколько серьезных научных проблем в истории ссылки поляков в Сибирь, в том числе первым определить количественные, структурные и географические характеристики этого явления. В третьей главе своей книги «Политические и государственные преступники» автор делает это следующим образом: «С весны 1863 года ... по 20 декабря 1866 года всего поступило в Сибирь, со включением и добровольно пришедших за ссыльными жен и детей, 18623 души обоего пола». Здесь же дана и динамика ссылки по годам: в 1863 г. -524 человека, в 1864 г. - 10649 , в 1865 г. - 4671 и в 1866 -м - 2829 ссыльных (между прочим, арифметическое сложение всех цифр дает нам несколько отличное от заявленного автором число в 18673 человека) [3, с. 179].

Далее С. В. Максимов, опять же первым, обозначает и видовую структуру ссылки участников Январского восстания. По его подсчетам, из 18623 поляков было отправлено на каторгу 3894 человека, на поселение -2153 , прислано на житье 2 254, сослано для водворения 8491, добровольно пришли за ссыльными 1830 членов семей (всего в сумме 18622 - опять же, пусть небольшое, но расхождение с заявленным общим количеством). При этом автор устанавливает, что бульшая часть поляков была распределена в Западную Сибирь (10 407 человек), а меньшая - в Восточную (8 199), «с той разницей, что в первую пришли с легчайшей виновностью, во вторую ушли приговоренные к самым тяжким наказаниям» $[3$, c. 180$]$.

Итак, имеем 18623 поляка, сосланных в Сибирь в 1863-1866 гг. за участие в Январском восстании.

Каким образом, на основе каких материалов С. В. Максимов получил эту цифру? К сожалению, автор не объясняет своему читателю методику подсчетов, нет у него и ссылок на использованные источники, что, уже само по себе, заставляет читателя несколько усомниться в достоверности результатов исследований.

При этом следует отметить, что на настоящий недостаток трудов С. В. Максимова уже указывалось в отечественной историографии. Так, еще в 1898 г. историк литературы А. М. Скабичевский, называя «Сибирь и каторгу» целой «эпопеей, в своем роде Илиадой и Одиссеей каторжной жизни», отмечал, что труд Максимова содержит весьма незначительное количество конкретных ссылок, работы же

\section{Baikal Research Journal}

электронный научный журнал Байкальского государственного университета 
«предшественников» если и цитируются, то делается это столь «вольно», что читатель не может порой отличить, где авторский текст, а где иллюстрация чужой мысли. «К сожалению, - пишет Скабичевский, - Максимов редко извещает читателя, из каких источников взял он те или другие факты» [4, с. 717].

Как видим, замечание существенное. Между тем - и это для нас главное - оно было оставлено без внимания, а затем количественные выводы С. В. Максимова были взяты на вооружение многими последующими исследователями этой темы, стали применяться ими без надлежащей критики, в качестве уже непогрешимого источника для построения своих научных концепций. Проиллюстрируем это положение надлежащими примерами, составленными в хронологическом порядке.

Одним из первых расчеты С. В. Максимова подхватил Дж. Кеннан. В России впервые его книга «Сибирь и ссылка» была издана в 1906 г. Ее документальной основой стали путевые очерки, написанные автором по поручению американского журнала «Century Magazine» во время путешествия через Сибирь в 1885-1886 гг. Рассказывая о тюрьмах Нерчинской системы, Кеннан пишет и о «тысячах польских повстанцев», сосланных сюда после 1863 г. Стремясь конкретизировать их численность, автор приводит целиком подсчеты С. В. Максимова - 18623 человека в целом, из них 8199 - в Восточной Сибири [5, с. 408$].$

И в Советский период нашей истории к подсчетам С. В. Максимова относились без должной критики. Так, в 1932 г. в Сибирской Советской энциклопедии появилась статья бывшего ссыльного, иркутянина М. М. Константинова «Каторга и ссылка в Сибири». Константинов дает значительный исследовательский материал об уголовной и политической ссылке в Сибирь со времен невольного пребывания в Братском остроге и Забайкалье протопопа Аввакума (1653-1663 гг.) до декрета Временного правительства начала марта 1917 г., объявившего политическую амнистию всем заключенным революционерам и отменившего политическую ссылку, в том числе и сибирскую. Не обходит вниманием автор и историю ссыльных поляков в Сибири, в том числе пребывание здесь участников Январского восстания. Говоря об этом времени, Константинов пишет: «Всего прибыло в Сибирь вместе с семьями в 1863 г. — 524 человека, в 1864 г. - 10649 , 1865 - 4671 , 1866 - 2 829. Из этого числа ушло на каторгу 3894 человека, на поселение 2 153, на житье 2254 и для водворения 8 491, добровольных - 1830 . По социальному положению большую часть ссыльных составляли дворяне, затем городские жители и крестьяне» [6, с. 591]. Как видим, М. М. Константинов целиком заимствует данные С. В. Максимова.

В 1936 г. Ф. А. Кудрявцев в книге «Александровский централ», делая широкий экскурс в историю карательной системы России, указывает, что «первой наиболее значительной группой политических ссыльных были участники польского восстания 1863 года». И далее определяет количество высланных в целом для Сибири - «до 18600 человек». При этом в Прибайкалье, по его данным, «поляки отбывали каторгу в Александровском винокуренном заводе, Усть-Кутских и Усольских соляных варницах, Петровском железоделательном заводе и рудниках Нерчинской каторги. До тысячи человек работали на постройке Кругобайкальского тракта» [7, с. 16-17].

Известно, что «Хрущевская оттепель» благотворно сказалась и на исторических исследованиях. В 1960-е гг. советские историки, в том числе и сибирские, заметно расширяли проблематику своих научных интересов, активно пересматривали отдельные положения и выводы, вводили в научный оборот новые, ранее недоступные источники. В этой связи заслуживает быть отмеченной особо книга Н. П. Митиной «Во глубине сибирских руд» (1966). Это первое монографическое исследование истории пребывания участников Январского восстания в Сибири, и

\section{Baikal Research Journal}

электронный научный журнал Байкальского государственного университета 
в первую очередь, в Прибайкалье. Н. П. Митина, говоря о высланных из Царства Польского, Литвы, Белоруссии и Украины за участие в восстании 1863-1864 гг. и опираясь на ведомости Министерства внутренних дел по 39 губерниям, называет уже 36459 человек в целом подвергшихся репрессиям, однако для Западной и Восточной Сибири количество ссыльных дает опять же ближе к Максимову 18606 человек. При этом автор структурно делит ссылку на водворение - «около 9000 человек», в каторжные работы - «около 4000 человек», на поселение - «не многим более 2000 человек» и «3 000 было выслано на жительство». [8, с. 11, 12].

Безраздельное господство подсчетов С. В. Максимова в отечественной историографии было нарушено С. Ф. Ковалем. В изданном в 1968 г. третьем томе «История Сибири», в параграфе «Политическая ссылка 60-80-х гг. XIX века», подготовленном этим ученым, встречаем иную, значительно бульшую цифру «Январских поляков»: «Общее число ссыльных повстанцев, - указано в тексте, превышало в Сибири 22 000. Осужденные на каторгу почти все, за исключением 11 человек, были отправлены в Иркутскую губернию и Забайкальскую область. В Восточную Сибирь были сосланы наиболее активные участники восстания, принадлежавшие к направлению «красных»... [9, с. 114].

Выводы С. Ф. Коваля нашли подкрепление в 1971 г. в известных «Очерках» по истории Иркутска. Ф. А. Кудрявцев и Г. А. Вендрих указывали: «В 60-х годах в Сибирь были сосланы участники восстания 1863-1864 гг. в Польше, Литве и Белоруссии. В исторической литературе количество их определялось в 18600 человек. Более точные подсчеты по документам, произведенные С. Ф. Ковалем, показали, что число каторжан и ссыльных по этому восстанию превышало 22000 человек [10, с. 111-112].

Казалось бы, с появлением данных С. Ф. Коваля подсчеты С. В. Максимова должны отойти на второй план. Однако уже 1971 г. В. Н. Дворянов в своей монографии опять указывает знакомые цифры: «с 1863 по 1867 г. в Тобольскую губернию, - пишет автор, - было сослано 4 101, в Томскую - 6306 , в Енисейскую -3719 , а в Иркутскую -4424 польских повстанца», а всего, следовательно, 18550 человек [11, с. 64-65].

Наконец в 1976 г. у Л. П. Рощевской в статье «Последний осколок приказной системы» обосновывается другое, нежели у Максимова и Коваля, количество ссыльных участников Январского восстания: «Всего за 1864-1869, 1876-1894 гг., то есть почти за 30 лет, - пишет автор, - в Сибирь поступило через Приказ [Тобольский. - A. И., С. К.] 25473 политических и государственных ссыльных. Из них - 23056 повстанцев 1863-1864 гг. (сосланных по суду с лишением прав 2870 , сосланных по распоряжению царского правительства (административно) без лишения прав - 509 человек, для водворения на казенных землях по политическим причинам - 18 816, без указания условий ссылки -493 , членов их семей - 368 человек)» [12, с. 207-208].

В 1983 г. Л. П. Рощевская уже в монографии подтвердила свои выводы, подчеркнув, что «в Сибирь сослали не 18 000, а 23056 повстанцев», причем, 10779 - в Западную Сибирь. [13, с. 40]. Значительно позже, в 2006 г., Л. П. Рощевская существенно изменила свои итоговые данные: «Всего, - утверждает автор, - было репрессировано более 36 тыс. человек, в том числе 22 тыс. отправлены в Западную Сибирь» [14, с. 87].

Постперестроечное время, к сожалению, мало что добавило к уже имеющимся количественным показателям участников Январского восстания, сосланным в Сибирь. Современные исследователи, далеко не всегда проводя собственные специальные широкие изыскания, по-прежнему опираются на результаты поисков своих предшественников. Так, западно-сибирский исследователь С. А. Мули-

\section{Baikal Research Journal}

электронный научный журнал Байкальского государственного университета 
на считает, что «в результате восстания в Сибирь было выслано около 20 тысяч поляков» [15, с. 496]. Похожие цифры встречаем и у С. В. Леончика: «более 22 тыс. поляков были осуждены и высланы в Сибирь, в Енисейскую губернию 3719 человек...» [16, с. 54].

Наконец в 2009 г. в Исторической энциклопедии Сибири, аккумулировавшей все наработанные за этот период результаты исследований, было сделано следующее заключение: «Численность репрессированных повстанцев, по официальным правительственным источникам, составляла около 18 тыс. чел. В общей сложности на каторгу, поселение, в воен. службу по суду, а также в административном порядке и под надзор властей до конца 1866 г. было сослано от 16 до 20 тысяч человек, в том числе на каторгу - $23 \%$, на поселение с лишением прав состояния $-12,8$, на жительство - 8, на вечное жительство - 50,5, в административном порядке $-5,7 \%$ » [17, стб. 645].

Как видим, отечественные историки, определяя количество ссыльных поляков в Сибири, сосланных за участие в Январском восстании, оперируют различными показателями, которые варьируются от 16 до 36 тыс. человек.

Ну, а каковы успехи польских ученых? Судя по имеющимся в нашем распоряжении опубликованным материалам, изучение этой проблемы началось в Польше с обретением независимости. В 1917 г. Бронислав Пилсудский в лекции, прочитанной в Польском доме в Лозанне под названием «Поляки в Сибири» указывал, что в течение 1863-1866 гг. в Сибирь «пошли почти 20 тыс. чел., половина которых были людьми образованными. Из этого числа около 4 тыс. осудили на каторжные работы (на поселение с лишением прав около 2,5 тыс.), столько же на временное поселение, около 2 тыс. семей добровольно пошли со ссыльными. Около 10 тыс. осуждены на вечное поселение без лишения прав. [18, с. 17].

Можно предположить, что цифра «почти 20 тыс. чел.», скорее всего, также заимствована у С. В. Максимова. В 1959 г. профессор Владыслав Евсевицкий, опять же специально не занимаясь этой проблемой, сделал вывод, о том, что «число сосланных в Сибирь за участие в восстании 1863 г. вместе с большим количеством добровольных изгнанников - членов семей, не исключая детей, следует, пожалуй, округлить до 30000 лиц» [1, с. 463]. В 1970-е гг. Хенрык Скок, подвергнув критике ставшую почти сакральной цифру в 18 тысяч поляков, высланных в Сибирь, обосновывает, опираясь на источники официального делопроизводства, новое для всей историографии число - 13018 ссыльных [1, с. 465].

Изучение сибирского периода жизни участников Январского восстания продолжалось и в новейший период польской истории. Наконец в 2002 г. был издан весьма содержательный сборник «Сибирь в истории и культуре польского народа», собравший на своих страницах все последние достижения российской и польской историографии. Примечательной для нашего вопроса является большая статья Софии Стшижевской под названием «Ссыльные участники Январского восстания». Автор впервые вводит в научный оборот материалы, хранящиеся в Главном архиве старых актов из фонда Управления генерал-полицеймейстера в Королевстве Польском. Эти данные «составляют 11 объемных томов, содержащих фамилии лиц, вывезенных из Польши в 101 арестантской партии в период с 1863 г. до 5 марта 1868 г. в европейскую часть России и в 90 эшелонах, отправленных прямо в Сибирь в период с декабря 1862 г. до 27 ноября 1874 г.». Имея такую уникальную информацию, а также опираясь на сводки Министерства внутренних дел России, отложившиеся в фондах ГАРФа, автор, пожалуй, впервые попыталась дать исчерпывающие (а главное обоснованные!) цифры поляков, отбывавших наказание каторгой и ссылкой в Сибири за участие в Январском восстании.

\section{Baikal Research Journal}

электронный научный журнал Байкальского государственного университета 
Анализ польских источников дал С. Стшижевской имена «около 13690 гражданских лиц, сосланных из Королевства Польского на поселение под надзор полиции в европейскую часть России, взятых там же в арестантские роты, а также приговоренных к поселению и каторжным работам непосредственно в Сибирь». Другой документ - «Отчет о количестве политических преступников, сосланных из Королевства Польского в империю на поселение... с момента ссылки до июня 1867 г.», составленный в Варшаве по заданию III Отделения и обнаруженный в ГАРФе, принес автору имена 11024 человек. Как видим, данные двух источников вполне сопоставимы, а значит, заслуживают доверия [19, с. 128-129].

Внимательный анализ текста статьи дает несколько неожиданный результат: оказывается в Сибирь из Польши попадало гораздо меньше участников восстания, бульшая часть отбывала наказание в Европейской России. Так, С. Стшижевская называет следующие цифры: на 1 января 1865 г. в Сибири было 2098 ссыльных из Польши, на 1 января 1866 г. - 2 823, в начале 1867 г. - 3049 , а в середине этого года, т. е. к первой частичной амнистии, сократившей число ссыльных, 3108 человек. Затем масштабы ссылки резко сократились: в 1867-1869 гг. в Сибирь поступило всего лишь 146 ссыльных, в 1869-1880-м годах - еще 77. Таким образом, по данным автора, в Сибирь за весь период ссылки участников Январского восстания поступило не более 3331 человека [19, с. 130].

Как видим, С. Стшижевская проделала весьма результативную работу. Остается только пожалеть, что ее данные касаются участников восстания лишь из Королевства Польского. Впрочем, автор в начале статьи, основываясь на сведениях МВД Российской империи, но не детализируя их, указывает, что в сентябре 1864 г. «Количество людей, вывезенных за участие в восстании 1863 г. из Королевства Польского, Литвы, Белоруссии и Украины, достигло 25 тыс.» [19, с. 127].

Выводы С. Стшижевской, основанные на оригинальных архивных материалах польских и российских архивов, что следует признать достаточно редким явлением, не стали, тем не менее, ориентиром для других польских исследователей: здесь наблюдаются значительные расхождения в итоговых подсчетах. В качестве примера приведем данные Дороты Михалюк, которая определила, что только в Сибирь за участие в Январском восстании было сослано «около 38 тысяч: из Королевства Польского - 38 \% , из Литвы и Белоруссии - 5 \%, с Украины - 5 \% . На каторгу выслано 10 \% осужденных в Сибирь, для остальных определялись различные формы поселения» [20, с. 118].

Д. Михалюк не единственный исследователь, апеллирующий столь значительными цифрами. Большинство современных польских историков в определении числа участников Январского восстания, наказанных ссылкой в Сибирь, сегодня склонны к значительному увеличению полученных когда-то итоговых цифр. Пример тому последняя крупная публикация Виктории Сливовской о побегах поляков из Сибири, вышедшая совсем недавно, в 2014 г. Так, говоря о цене, которую Польша заплатила за независимость от России, автор указывает, что «картотека высланных после Январского восстания» насчитывающая «40 тысяч имен, ...безусловно, не охватывает всех репрессированных», эти данные, полагает автор, «бесспорно, занижены» и речь идет о «первой в истории массовой депортации его участников вглубь империи». $[21$, с. 20]. Ян Зюлек, анализировавший мемуарное наследие «сибирских поляков» периода 1860-х гг., обращает внимание на наличие в нем еще более значительных цифр - 80-100 тыс. ссыльных - участников Январского восстания [22, с. 135].

Итак, историографический анализ отечественной и польской литературы заставляет нас сделать, по крайней мере, три обобщающих вывода. Прежде всего, очевидно, что и сегодня среди ученых не существует единого мнения о количестве участников Январского восстания, сосланных в Сибирь. Конечные данные их ис-

\section{Baikal Research Journal}

электронный научный журнал Байкальского государственного университета 
следований существенно разнятся - от 16 до 36 тыс. - в отечественной историографии и от 13 до 100 тыс. человек - в польской. Такое расхождение - яркое свидетельство того, что настоящая научная проблема до сих пор далека от своего решения. Во-вторых, значительная "разноголосица» итоговых цифр - отражение весьма сложной (а нередко и противоречивой) источниковой базы проблемы. Ее квалифицированное прочтение требует объединения усилий, как польских, так и российских специалистов с целью скоординированного, отдельного изучения с привлечением новых, ранее не вводимых в научный оборот материалов. И последнее: установление подлинной численности участников Январского восстания могло бы значительно скорректировать некоторые обобщающие положения специалистов в области политической истории России и Польши второй половины XIX - начала XX в. в целом.

\section{Список использованной литературы}

1. Шостакович Б. С. Феномен польско-сибирской истории (XVII в. - 1917 г.): основные аспекты современных научных трактовок, результатов и задач дальнейшей разработки темы / Б. С. Шостакович. - М. : МИК, 2015. - 752 с.

2. Энциклопедический словарь : в 86 т. / под ред. К. К. Арсеньева, О. О. Петрушевского ; изд. Ф. А. Брокгауз [Лейпциг], И. А. Ефрон [Санкт-Петербург]. - СПб. : Семен. типолитогр. И. А. Ефрона, 1896. - Т. XVIII. - 480 с.

3. Максимов С. В. Собрание сочинений : в 7 т. / С. В. Максимов. - М. : Кн. клуб Книговек, 2010. - Т. 2: Сибирь и каторга. Ч. II-IV. - 640 с.

4. Скабичевский А. М. Каторга пятьдесят лет тому назад и ныне / А. М. Скабичевский // Русская мысль. - 1898. - Кн. IX-X. - С. 685-746.

5. Кеннан Дж. Сибирь и ссылка / Дж. Кеннан. - СПб. : Изд. В. Врублевского, 1906. $-460 \mathrm{c}$.

6. Константинов М. Каторга и ссылка в Сибири / М. Константинов // Сибирская Советская энциклопедия : в 4 т. / под ред. Б. З. Шумяцкого, А. А. Ансона, М. М. Басова. Новосибирск : Зап.-Сиб. отд-ние ОГИЗ, 1931. - Т. 2. - С. 575-622.

7. Кудрявцев Ф. А. Александровский централ / Ф. А. Кудрявцев. - Иркутск : Вост.Сиб. крайиздат, 1936. - $100 \mathrm{c.}$

8. Митина Н. П. Во глубине сибирских руд. К столетию восстания польских ссыльных на Кругобайкальском тракте / Н. П. Митина. - М. : Наука, 1966. - 145 с.

9. История Сибири с древнейших времен до наших дней : в 5 т. / под ред. А. П. Окладникова, В. И. Шункова. - Л. : Наука, Ленингр. отд-ние, 1968. - Т. 3: Сибирь в эпоху капитализма. - $530 \mathrm{c.}$

10. Кудрявцев Ф. Иркутск. Очерки по истории города / Ф. А. Кудрявцев, Г. Вендрих. - Иркутск : Вост.-Сиб. кн. изд-во, 1971. - 436 с.

11. Дворянов В. Н. В Сибирской дальней стороне... (Очерки истории царской каторги и ссылки. 60-е годы XVIII в. - 1917 г.) / В. Н. Дворянов. - Минск : Наука и техника, 1971. - 333 c.

12. Рощевская Л. П. Последний осколок приказной системы / Л. П. Рощевская // Вопросы истории. - 1976. - № 12. - С. 203-208.

13. Рощевская Л. П. Революционеры-разночинцы в западносибирском изгнании / Л. П. Рощевская. - Л. : Изд-во Ленингр. ун-та, 1983. - 176 с.

14. Рощевская Л. П. История политических репрессий в царской России : учеб. пособие / Л. П. Рощевская. - Сыктывкар : Изд-во Сыктывк. гос. ун-та, 2006. - 140 с.

15. Мулина С. А. Участники Польского восстания 1863 г. в Сибири: проблемы адаптации / С. А. Мулина // Азиатская Россия: люди и структуры империи : сб. науч. ст. Омск : Изд-во Ом. гос. ун-та, 2005. - С. 496-509.

16. Леончик С. Поляки юга Енисейской губернии. История ссылок и заселения / С. Леончик // Сибирь в истории и культуре польского народа : пер с пол. / под ред. А. Кучинского, С. П. Романова. - М. : Ладомир, 2002. - С. 52-58.

17. Поляки / Р. В. Оплаканская, А. И. Савин, Е. Н. Туманик, Б. С. Шостакович // Историческая энциклопедия Сибири : в 3 т. / под ред. В. А. Ламина. - Новосибирск : Ист. наследие Сибири, 2009. - Т. 2. - Стб. 644-649.

\section{Baikal Research Journal}


18. Пилсудский Б. Поляки в Сибири / Б. Пилсудский // Сибирь в истории и культуре польского народа : пер с пол. / под ред. А. Кучинского, С. П. Романова. - М. : Ладомир, 2002. - C. $13-30$.

19. Стшижевская С. Ссыльные участники Январского восстания / С. Стшижевская // Сибирь в истории и культуре польского народа : пер с пол. / под ред. А. Кучинского, С. П. Романова. - М. : Ладомир, 2002. - С. 124-134.

20. Михалюк Д. Участники манифестации 1861 г. и Январского (1863 г.) восстания на Гродненщине - ссыльные в Сибирь / Д. Михалюк // Сибирско-польская история и современность: актуальные вопросы : материалы Междунар. науч. конф. Иркутск, 11-15 сент. 2000 г. - Иркутск : Изд-во Обл. юнош. б-ки, 2001. - С. 117-119.

21. Сливовская В. Побеги из Сибири : пер. с пол. / В. Сливовская. - СПб. : Алетейя, 2014. - 536 с. - (Сер. Польско-сибирская библиотека).

22. Зюлек Я. Римско-католические священники, сосланные в Сибирь после Январского восстания / Я. Зюлек // Сибирь в истории и культуре польского народа : пер с пол. / под ред. А. Кучинского, С. П. Романова. - М. : Ладомир, 2002. - С. 135-145.

\section{References}

1. Shostakovich B. S. Fenomen pol'sko-sibirskoi istorii (XVII v. - 1917 g.). Osnovnye aspekty sovremennykh nauchnykh traktovok, rezul'tatov $i$ zadach dal'neishei razrabotki temy [Phenomenon of the Pole-Siberian history (17th century - 1917) Main aspects of present-day scientific interpretations, results and further development of the topic]. Moscow, MIK Publ., 2015. $752 \mathrm{p}$.

2. Brokgauz F. A., Efron I. A. (eds). Entsiklopedicheskii slovar' [Encyclopedic Dictionary]. Saint Petersburg, Efron I. A. Publ., 1896. Vol. 18. 480 p.

3. Maksimov S. V. Sobranie sochinenii [Collection of Works]. Moscow, Knizhnyi Klub Knigovek Publ., 2010. Vol. 2. 640 p.

4. Skabichevsky A. M. Hard labors fifty years ago and at present. Russkaya mysl', 1898, books 9-10, pp. 685-746. (In Russian).

5. Kennan Dzh. Sibir' i ssylka [Siberia and exile]. Saint Petersburg, V. Vrublevsky Publ., 1906. $460 \mathrm{p}$.

6. Konstantinov M. Hard labors and exile in Siberia. In Shumyatsky B. Z., Anson A. A., Basov M. M. (eds). Sibirskaya Sovetskaya entsiklopediya [Siberian Soviet Encyclopedia]. Novosibirsk, We4st-Siberian branch of OGIZ, 1931, vol. 2, pp. 575-622. (In Russian).

7. Kudryavtsev F. A. Aleksandrovskii tsentral [Aleksandrovsky Central]. Irkutsk, Vostochno-Sibirsky kraiizdat Publ., 1936. 100 p.

8. Mitina N. P. Vo glubine sibirskikh rud. K stoletiyu vosstaniya pol'skikh ssyl'nykh na Krugobaikal'skom trakte [In the depth of Siberian ore mines. To the century of Polis exiles revolt on the Round-Baikal road]. Moscow, Nauka Publ., 1966. 145 p.

9. Okladnikov A. P., Shunkov V. I. (eds). Istoriya Sibiri s drevneishikh vremen do nashikh dnei [History of Siberia from ancient times till our days]. Leningrad, Nauka Publ., 1968. Vol. 3. 530 p.

10. Kudryavtsev F., Vendrikh G. Irkutsk. Ocherki po istorii goroda [Irkutsk. Essays on history of the town]. Irkutsk, East Siberian Publishing, 1971. $436 \mathrm{p}$.

11. Dvoryanov N. V. V sibirskoi dal'nei storone... Ocherki istorii tsarskoi katorgi $i$ ssylki. 60-e gody XVIII v. - $1917 \mathrm{~g}$. [On the far side of Siberia... Short notes on penal servitude and exile in 1760-1917]. Minsk, Nauka i tekhnika Publ., 1971. 333 p.

12. Roshchevskaya L. P. The last remaining part of the mandatory system. Voprosy istorii $=$ Issues of History, 1976, no. 12, pp. 203-208. (In Russian).

13. Roshchevskaya L. P. Revolyutsionery-raznochintsy v zapadnosibirskom izgnanii [Revolutionaries-commoners in East-Siberian exile]. Leningrad State University Publ., 1983. 176 p.

14. Roshchevskaya L. P. Istoriya politicheskikh repressii $v$ tsarskoi Rossii [History of political repressions in the Tsar Russia]. Syktyvkar State University Publ., 2006. 140 p.

15. Mulina S. A. Participants of 1863 Polish revolt in Siberia: problems of adaptation. Aziatskaya Rossiya: lyudi $i$ struktury imperii [Asian Russia: people and structure of the empire]. Omsk State University Publ., 2005, pp. 496-509. (In Russian).

16. Leonchik S. Poles of the south of Yenisei Province. History of exile procedures and settlements. In Kuchinsky A., Romanov S. P. (eds). Sibir'v istorii i kul'ture pol'skogo naroda

\section{Baikal Research Journal}


[Siberia in history and culture of the Polish people]. Moscow, Ladomir Publ., 2002, pp. 52-58. (In Russian).

17. Oplakanskaya R. V., Savin A. I., Tumanik E. N., Shostakovich B. S. Poles. In Lamin V. A. (ed.) Istoricheskaya entsiklopediya Sibiri [Historical encyclopedia of Siberia]. Novosibirsk, Historical Heritage of Siberia Publ., vol. 2, col. 644-649. (In Russian).

18. Pilsudskii B. Poles in Siberia. In Kuchinskii A., Romanov S. P. (eds). Sibir' $v$ istorii $i$ kul'ture pol'skogo naroda [Siberia in history and culture of the Polish people]. Moscow, Ladomir Publ., 2002, pp. 13-30. (In Russian).

19. Stshizhevskaya S. The exiled participants of January revolt. In Kuchinsky A., Romanov S. P. (eds). Sibir' $v$ istorii i kul'ture pol'skogo naroda [Siberia in history and culture of the Polish people]. Moscow, Ladomir Publ., 2002, pp. 124-134. (In Russian).

20. Mikhalyuk D. Participants of 1981 manifestation and January revolt (1983) Hrodna vicinity - exiles to Siberia. Sibirsko-pol'skaya istoriya i sovremennost': aktual'nye voprosy. Materialy mezhdunarodnoi nauchno-prakticheskoi konferentsii, Irkutsk, 11-15 sentyabrya 2000 g. [Siberian-Polish history and modern times: topical issues. Materials of International Research Conference, Irkutsk, September 11-15, 2000]. Irkutsk, Regional Youth Library Publ., 2001, pp. 117-119. (In Russian).

21. Slivovskaya V. Pobegi iz Sibiri [Runaways from Siberia]. Saint Petersburg, Aleteiya Publ., 2014. 536 p.

22. Zyulek Ya. Roman and Catholic priests exiled to Siberia after January revolt. In Kuchinsky A., Romanov S. P. (eds). Sibir' $v$ istorii $i$ kul'ture pol'skogo naroda [Siberia in history and culture of the Polish people]. Moscow, Ladomir Publ., 2002, pp. 135-145. (In Russian).

\section{Информация об авторах}

Иванов Александр Александрович - доктор исторических наук, профессор, кафедра политологии, истории и регионоведения, Иркутский государственный университет, 664003, Иркутск, ул. К. Маркса, 1; e-mail: ottisk@irmail.ru.

Кузнецов Сергей Ильич - доктор исторических наук, профессор, заведующий кафедрой мировой истории и международных отношений, Иркутский государственный университет, 664025, Иркутск, ул. Чкалова, 2; e-mail: s.kuznetsov@mail.ru.

\section{Authors}

Aleksandr A. Ivanov - Doctor habil. (History), Professor, Chair of Political Science and Russian History, Irkutsk State University, 1 K. Marx St., 664003, Irkutsk, Russian Federation; e-mail: ottisk@irmail.ru.

Sergey I. Kuznetsov - Doctor habil. (History), Professor, Head of Chair of World History and International Relations, Irkutsk State University, 2 Chkalov St., 664025, Irkutsk, Russian Federation; e-mail: s.kuznetsov@mail.ru.

\section{Библиографическое описание статьи}

Иванов А. А. К определению количества сосланных в Сибирь участников Январского восстания 1863 года / А. А. Иванов, С. И. Кузнецов // Baikal Research Journal. — 2016. T. 7, № 6. - DOI: 10.17150/2411-6262.2016.7(6).17.

\section{Reference to article}

Ivanov A. A., Kuznetsov S. I. On determining the number of the January 1863 revolt participants exiled to Siberia. Baikal Research Journal, 2016, vol. 7, no. 6. DOI: 10.17150/24116262.2016.7(6).17. (In Russian).

\section{Baikal Research Journal}

